Session 1712

\title{
NSF Combined Research and Curriculum Development on Multiphase Transport Phenomena
}

\author{
M. J. Amey ${ }^{2}$, A. Bénard ${ }^{2}$, G. G. Chase ${ }^{1}$, E. A. Evans ${ }^{1}$, \\ K. Jayaraman', R. S. Mohan ${ }^{3}$, S. M. Parks' ${ }^{2}$, C. A. Petty ${ }^{2}$ (presenter), \\ O. Shoham ${ }^{3}$, S. A. Shirazi ${ }^{3}$, K. D. Wisecarver ${ }^{3}$, M. Zhuang ${ }^{2}$ \\ ${ }^{1}$ The University of Akron $/{ }^{2}$ Michigan State University $/{ }^{3}$ The University of Tulsa
}

\section{Summary}

This curriculum development project on multiphase transport phenomena draws on the research experiences from nine research laboratories at The University of Akron, Michigan State University, and the University of Tulsa. The objective of the project is to develop a new curriculum for teaching undergraduate and graduate students multiphase computational fluid dynamics for advanced design.

The impact of multiphase flow research on solving practical engineering problems is an integral part of the learning experience. Industrial participants in the project provide specific design problems related to emerging technologies. Students are taught the fundamentals of computational fluid dynamics (CFD) during a one-week workshop. This is followed by an Internet course on multiphase transport phenomena. The students work in teams on CFD design problems with a faculty and industrial mentor. The salient results of this NSF/CRCD project are presented in this paper.

\section{Introduction}

Courses on transport phenomena associated with multicomponent, single-phase fluids play a major role in training undergraduate and graduate students in chemical, mechanical, and petroleum engineering. However, like thermodynamics and other multidisciplinary courses, these academic offerings have been developed separately within each engineering discipline in order to emphasize applied problems encountered in each field. So far, student training in the area of transport phenomena for multiphase fluids has been limited to specialized courses and workshops. Consequently, important advances in multiphase flow research and analysis tend to remain isolated within a discipline. Moreover, access to post graduate courses on multiphase transport phenomena and particulate processing remains a difficult challenge for most graduates. Therefore, the objective of this NSF- Combined Research and Curriculum Development (CRCD) initiative is to bridge the gap between traditional training in fluid mechanics, heat transfer, and mass transfer received by most 
engineers within their individual discipline and the need for additional specialization and training in the area of multiphase transport phenomena (Willis et al., 1991; Dullian, 1992; Hornung, 1997).

Recent advances in multiphase flow research have been achieved due to the availability of laser-based flow instrumentation, inexpensive computing systems, and improved computational protocols. These enabling technologies provide new opportunities for innovative process equipment design. Thus, this NSF/CRCD project aims to develop and implement a multi-institutional curriculum on multiphase transport phenomena (MTP) that builds on the existing course offerings in the participating departments. The new MTP course will be designed to 1) train students from different engineering backgrounds in the use of multiphase computational fluid dynamics (MCFD); 2) introduce students to state-of-the-art experimental techniques employed to validate multiphase transport models; and, 3) teach students how to critically analyze and interpret CFD results. The MCFD offering will eventually be integrated into the existing coursework structure and degree requirements of the participating departments. Modular educational packages appropriate for undergraduate instruction and/or entry level graduate instruction will be developed as complementary material to more traditional courses on transport phenomena.

\section{Need for a Multiphase Transport Phenomena Curriculum}

Multiphase transport phenomena research is of industrial and national importance. Advances in oil and gas production, composite material processing, bioremediation of soils, plastic recycling, modern biotechnology reactors and separators, high-performance filtration devices, nuclear fuel reprocessing, and efficient automotive fuel utilization represent a few disparate engineering problems that rely on a basic fundamental understanding of multiphase transport phenomena.

This curriculum development initiative aims to address a need to bridge an educational gap between undergraduate training in transport phenomena of single-phase fluids as exemplified by Bird et al. (2002) and transport phenomena of multiphase fluids (see, esp., Gidaspow, 1994; Drew and Passman, 1999). Moreover, a significant gap is developing on the use of conventional transport phenomena principles and computational fluid dynamic tools in the area of single-phase and multiphase turbulent flows (Crow et al., 1996; Pope, 2000). CFD has opened the possibilities of analyzing in the classroom flows in complex geometries unimagined ten to twenty years ago. However, students need further training to effectively use modern CFD codes and to understand how CFD results can be used as an innovative process design and diagnostic tool.

\section{Participants}

The participants in this project come from industry and academia. The broad goals of this initiative stem directly from ongoing research and educational programs in chemical, mechanical, and petroleum engineering at The University of Akron, Michigan State University, and The University of Tulsa. The multi-disciplinary, multi-institutional curriculum development project intends to integrate different teaching paradigms associated with these three professional groups. The industrial 
participants are engineers from AEA Technology Engineering Software Inc., Bechtel Technology and Consulting, ChevronTexaco, The Dow Chemical Company, DuPont Central Research \& Development, Eastman Chemical Company, ExxonMobile Production Company, Fluent Incorporated, Krebs Engineers, Pharmacia, The Procter \& Gamble Company, and The Trane Company.

\section{Goals of the Project}

The overall goal of this effort is to develop and implement a multiphase transport phenomena course across professional disciplines. The structure of the curriculum addresses the following eight educational needs for advanced undergraduate students, beginning graduate students, and industrial postgraduate students: 1) training in fundamentals of multiphase transport phenomena; 2) training in the development of multiphase model formulation, interpretation, and experimental validation; 3 ) training in the fundamentals of numerical methods that support current state-of-the-art commercial CFD codes; 4) training in the implementation of CFD codes; 5) training in the use of CFD codes for non-turbulent flows of single phase fluids; 6) training in the use of CFD codes for turbulent flows of single phase fluids; 7) training in the application of multiphase CFD codes; and, 8) training in the integration of CFD tools into the design process.

\section{Organization of the Training Program}

The program is organized into three major parts: a one-week CFD bootcamp; an intense Internet course on multiphase transport phenomena; and, an interdisciplinary/interuniversity design project.

\section{Elements of the CFD bootcamp}

The CFD bootcamp was conducted at MSU for a week in August of 2000 and for a week in June of 2001. The bootcamp had periods of intense training interspersed with social activities such as picnics and baseball games (Lansing Lugnuts). Approximately twenty undergraduate and graduate students participated along with five faculty and six industrial mentors each year. The students reviewed key ideas associated with single-phase transport phenomena, conducted practical hands-on experiments related to single phase and multiphase materials and learned to use a commercial CFD code (i.e., CFX during the first year and Fluent during the second year). At the end of the CFD software training sessions, the students understood the fundamentals and had experience in setting up and executing solutions to simple computational problems.

During the CFD bootcamp, each student was assigned to a design team. The students met with industrial mentors to discuss the case studies and to identify the scope of the CFD design project. Part of the training at the bootcamp included a discussion on the state-of-the-art of CFD software, its limitations, and interpretation of results. These discussions were provided by AEA Technology Inc. and by Fluent Inc. At the end of the bootcamp, each of the design teams presented their plan on how they were going to solve the problems proposed by the industrial mentors. The students were given 
instruction on how to interact through e-mail and a bulletin board supported by the Virtual University Group at Michigan State University.

\section{Elements of the Internet course}

An Internet course complements an ongoing CFD design experience by introducing the students to multiphase transport phenomena models. The Internet course has three components: multiphase transport phenomena fundamentals; gas-liquid flow pattern predictions; and, flow through porous media. A preview of this activity is located at www.vu.msu.edu/preview/eng-mtp.

\section{Industrial CFD Case Studies}

Five industrial CFD case studies have been completed by the student teams. The following table lists the name and affiliation of each team member. A brief summary of each project follows.

Table 1. CFD Design Team Members

\begin{tabular}{|c|c|c|c|c|c|c|}
\hline Team & Company & $\begin{array}{c}\text { Host } \\
\text { University }\end{array}$ & $\begin{array}{c}\text { Industrial } \\
\text { Advisor }\end{array}$ & $\begin{array}{c}\text { Academic } \\
\text { Advisor }\end{array}$ & $\begin{array}{c}\text { Graduate Student } \\
\text { Mentor }\end{array}$ & $\begin{array}{c}\text { Undergraduate } \\
\text { Student }\end{array}$ \\
\hline A & Pharmacia & MSU & Mark Widman & Charles Petty & YoChan Kim & $\begin{array}{c}\text { Christina Berger } \\
\text { Carl Rose } \\
\text { Andy Yoder }\end{array}$ \\
\hline B & Trane & MSU & Ray Rite & $\begin{array}{c}\text { André Bénard } \\
\text { Mei Zhuang }\end{array}$ & $\begin{array}{c}\text { Figan Lacin } \\
\text { Dilip Mandal }\end{array}$ & $\begin{array}{c}\text { Dina El-dein } \\
\text { Nick Lynn }\end{array}$ \\
\hline C & $\begin{array}{c}\text { Eastman } \\
\text { Chemical }\end{array}$ & Akron & Kevin Fontenot & $\begin{array}{c}\text { George Chase } \\
\text { Edward Evans }\end{array}$ & $\begin{array}{c}\text { Brian Raber } \\
\text { Hongmin Li }\end{array}$ & $\begin{array}{c}\text { Kathryn Baker } \\
\text { Troy Hendricks } \\
\text { Sara Vermillion }\end{array}$ \\
\hline D & $\begin{array}{c}\text { Chevron- } \\
\text { Texaco }\end{array}$ & Tulsa & Gene Kouba & $\begin{array}{c}\text { Ram Mohan } \\
\text { Ovadia Shoham }\end{array}$ & Luis Gomez & $\begin{array}{c}\text { Floyd Hammond } \\
\text { Steven Leibrandt } \\
\text { Jose Severino }\end{array}$ \\
\hline E & $\begin{array}{c}\text { Krebs } \\
\text { Engineers }\end{array}$ & MSU & Tim Olson & Steven Parks & $\begin{array}{c}\text { Luwi Oluwole } \\
\text { William Wehbe }\end{array}$ \\
\hline
\end{tabular}




\section{Team A: Pharmacia Case Study}

Numerical Simulation of a Solid/Fluid Suspension in an Enclosed Tank

Project Summary. Maintaining a uniform suspension in a feed tank is an important unit operation in the pharmaceutical industry. Engineers at Pharmacia in Kalamazoo, Michigan use a perforated vibrating disk situated on the axis and near the bottom of a feed tank to suspend solid drug particles in an aqueous suspending medium. The perforations in the vibromixer are conical in shape and create a jet-like flow through each hole. This action provides a means to transfer momentum from the vibrating solid plate to the fluid. In this study, the pumping action of the vibromixer is simulated by an axisymmetric round jet. The simulation examines the influence of the liquid level, the position of the momentum source, and the jet velocity on the spatial uniformity of a suspension of $10 \mu \mathrm{m}$-diameter solid particles (density $=1,193 \mathrm{~kg} / \mathrm{m}^{3}$ ) predicted by an algebraic slip mixture model for two-phase flows (Manninen et al., 1996; Ivanov et al., 1999). The results indicate that 1) once mixed, the solid/fluid suspension remains well mixed for the range of conditions studied; and, 2) the jet velocity influences the mixing time significantly whereas the location of the vibromixer and the liquid holdup have only a minor, but noticeable, impact on the extent of mixing.

Team B: The Trane Company

Numerical Simulation of Flow within a HVAC Header

Project Summary. The purpose of a header in a heating, ventilation and air conditioning (HVAC) system is to distribute a refrigerant with the same quality and mass flow rate to each evaporator. Engineers at the Trane Company in La Crosse, Wisconsin are exploring different designs to accomplish this task. One specific proposal is to use a large diameter vertical tube with equally spaced 12-mm diameter branch tubes as a header. The primary goal of this CFD study is to determine the backpressure needed at the outlets of each branch tube to satisfy the HVAC system requirements. A secondary goal is to study the effects of the number of branch tubes and the droplet diameter of the vapor phase on the maldistribution of flow and the quality of the refrigerant delivered to each evaporator. In this study, the multiphase turbulent flow within the distribution manifold is simulated by using an algebraic slip mixture model (see Manninen et al., 1996; Ivanov et al., 1999). The simulation identifies the required backpressure on each outlet tube needed to deliver the same mass flow rate and quality of refrigerant to all evaporators. The multiphase model shows that large liquid droplets (i.e., diameter $>50 \mathrm{~mm}$ ) can accumulate in the lower portion of the feeder due to secondary flows. 
Eastman Chemical Company

Numerical Simulation of a Bubble Column

Project Summary. Large slurry bubble columns (SBC) are important in the chemical and biochemical industries where three-phase reactions are common. SBC-reactors are used by Eastman Chemical Company in Kingsport, Tennessee to manufacture specialty chemicals. The purpose of this project is to determine the effect of sparger ring diameter, $\mathrm{D}_{\mathrm{S}}$, and gas flow rate, $\mathrm{Q}_{\mathrm{G}}$, on the liquid phase residence-time-distribution in a bubble column. In this CFD study, an algebraic slip mixture model (see Manninen et al., 1996; Ivanov et al., 1999) is used to simulate an air/water mixture in a column of diameter $\mathrm{D}(=2.4 \mathrm{~m})$ and height $\mathrm{H}(=19.2 \mathrm{~m})$. The volume of the column, $\mathrm{V}$, is approximately 91 $\mathrm{m}^{3}$. The volumetric flow rate of the liquid phase, $\mathrm{Q}_{\mathrm{L}}$, is about $89 \mathrm{~m}^{3} / \mathrm{h}$; the gas rate, $\mathrm{Q}_{\mathrm{G}}$, is varied from $\sim 800 \mathrm{~m}^{3} / \mathrm{h}$ to $\sim 2,400 \mathrm{~m}^{3} / \mathrm{h}$. Thus, for the conditions studied, the superficial mean residence time of the liquid phase is about 3,600s whereas the superficial mean residence time for the gas phase ranges from $137 \mathrm{~s}$ at the high gas rate to $410 \mathrm{~s}$ at the low gas rate. Simulations were de veloped for $\mathrm{D} / \mathrm{D}_{\mathrm{S}}$ from $8 / 3$ to $8 / 6$. The aspect ratio of the column was fixed at $H / D=64 / 8$. The results show that the mean residence time of the liquid phase is approximately 700 s for $\mathrm{D} / \mathrm{D}_{\mathrm{S}} \cong 8 / 4$. This implies that the liquid holdup in the column is about $17 \mathrm{vol} . \%$ of the mixture volume. The simulation reveals that regions of very high concentrations of the dispersed phase develop in an annular zone above the sparger and at the top of the column. This segregation of the air and water phases limits the contact time available for mass transfer.

\section{ChevronTexaco}

\section{CFD Study of a Water/Oil Dispersion in a Distribution Manifold}

Project Summary. Wet crude oil gravity separation tanks play an essential role in the production of crude oil and are often deployed upstream of a desalting operation. The capacity of these tanks may be as large as 80,000 barrels $\left(13,392 \mathrm{~m}^{3}\right)$ and may process $60,000 \mathrm{bpd}\left(9,600 \mathrm{~m}^{3} /\right.$ day $)$ of wet crude oil containing $20 \mathrm{vol} \%$ water. As an oil field ages, the water cut increases and the separation performance of the gravity separator declines. Engineers at ChevronTexaco in Houston, Texas have recently simulated the performance of large-scale gravity separators to better understand the relationship between water cut and separation performance. An important assumption employed in previous studies is that the wet crude oil is uniformly distributed near the bottom of the tank. In this study, the flow of the water/oil mixture through a skeleton-like spreader system consisting of a 24"diameter backbone pipe with smaller 12"-diameter branch lines is simulated by using an algebraic slip mixture model. Multiple effluent slots are uniformly positioned along the individual branch lines. The simulation examines the influence of feed rate on the maldistribution of the water/oil mixture within the spreader geometry predicted by the algebraic slip mixture model (Manninen et al., 1996; Ivanov et $a l ., 1999)$. The calculations show that the pressure in the large feeder pipe increases in the direction of flow and that a nonuniform distribution of water and oil occurs due to secondary flows associated with flow splitting into the smaller branch lines. The current study predicts the flow rate, the water/oil ratio, and the pressure drop across the small slots in the branch lines. This information is needed to estimate the size of the water drops introduced into the gravity separator. 
Krebs Engineers

Influence of Cone Angle and Capacity on Hydrocyclone Separators

Project Summary. Hydrocyclone classifiers are used in closed circuit grinding operations to control the size distribution of mineral ores prior to flotation. Recently, Krebs Engineers of Tucson, Arizona introduced a new class of hydrocyclone classifiers with a double cone design. The new design, referred to as the $\mathrm{gMAX}^{\circledR}$ cyclone, has a relatively low separation cut size $(\sim 60 \mu \mathrm{m})$ and a high capacity $\left(\sim 77 \mathrm{~m}^{3} / \mathrm{h}\right)$. In this CFD study, the turbulent flow field within a $254 \mathrm{~mm}$-diameter gMAX $^{\circledR}$ cyclone is simulated using the standard k- $\varepsilon$ model for the Reynolds stress. The entrainment of an air core on the axis of the hydrocyclone is eliminated in the simulation by imposing a spatially uniform backpressure on the overflow and underflow streams. A discrete-phase particle tracking technique is used to evaluate the separation performance of the hydrocyclone classifier. The flow patterns within a $10.5^{\circ}$ - and $20^{\circ}$ - single cone are compared with the flow patterns that develop within the new $20^{\circ} / 6^{\circ}$ double cone design. Simulations for the three hydrocyclones are developed for two feed rates: 35 $\mathrm{m}^{3} / \mathrm{h}$ and $60 \mathrm{~m}^{3} / \mathrm{h}$. The results show that the volumetric flow split is independent of capacity and shape, with approximately 75 vol. $\%$ of the feed stream exiting through the overflow nozzle. The predicted pressure drop across the hydrocyclone is much lower than observed in field tests, but this type of result is symptomatic of the turbulence model employed. Although the $\mathrm{D}_{50}$-cut size of the separator predicted by the simulation is larger than expected, qualitative comparisons among the three designs are self-consistent. The simulation shows that the $\mathrm{D}_{50}$-cut size decreases with an increase in the inlet velocity and, most significantly, that the $\mathrm{D}_{50}$-cut sizes for the $20^{\circ}$ cyclone and the gMAX $^{\circledR}$ cyclone are essentially the same for a feed rate of $60 \mathrm{~m}^{3} / \mathrm{h}$.

\section{Assessment/Evaluation}

The curriculum development project was supported by on-going assessment and evaluation processes. A pre- and post-bootcamp assessment was conducted, along with a mid-week evaluation during the camp. Expectations of the students for learning outcomes, team development and teamwork, and online capabilities and on-line work were assessed and monitored throughout the bootcamp. Industrial expectations for the overall design project, perception of return on investment, and utility of participation was assessed at the end of the bootcamp. During the on-line course, a mid-term assessment was conducted. Students commented on learning gains over the course material, time investment in the on-line experience and design project, comfort with on-line learning environments, and general satisfaction with the various aspects of the project. A final standardized on-line course evaluation was also used, in compliance with MSU faculty guidelines. Because of the perceived centrality of the Webtalk bulletin board for intra-team and class participation, content analyses of the on-line postings were also conducted. Themes and patterns about nature, content, frequency of communication were developed that have implications for on-line student teams, design projects and curriculum design. A summary of the project assessment and evaluation will be presented at the meeting. 
Acknowledgements:

This project was funded by NSF under the Combined Research Curriculum Development program (ECC-9980325). Sun Microsystems partially funded the acquisition of workstations for the three universities. The authors sincerely appreciate the support, encouragement, and suggestions from Mary Poats, our NSF program manager.

The authors also acknowledge with thanks important technical support from the following individuals: Jeffery Henning of AEA Technologies and Kumar Dhanasekharam, Ahmad Haidari, Barbara Hutchings, and Sandeep Sovani of FLUENT, Inc. for their timely contributions in the use of commercial CFD codes; Jackie Carlson and Fred Hall of the Division of Engineering Computer Services at Michigan State University (MSU) for hardware and software support; and, Randy Russell, Chanelle Hughey, and Loraine Hudson of the Virtual University at MSU for their ongoing support of the project preview site and of the Internet course on Multiphase Transport Phenomena.

The authors sincerely thank the industrial participants for their advice and sticking with us on this risky and exploratory project. The project would not have been possible without the in kind support from Jon Berkoe and Brigette Rosendall of Bechtel; Gene Kouba and Joseph Shen of ChevronTexaco; Paul Gillis of Dow Chemical; Karsten Keller of DuPont; Kevin Fontenot of Eastman Chemical; Stephen Lyons of ExxonMobil; Mark Hoyack and Tim Olson of Krebs Engineers; Mark Widman of Pharmacia; Savas Aydore of Proctor \& Gamble; and Ray Rite of the Trane Company.

Finally, the project would not have been possible without the support of the graduate and undergraduate student participants. The authors acknowledge with thanks the contributions of the following first-year and second-year students: The University of Akron ... Joshua Herron, Seth Jentner, Hongmin Li, Brian Raber, Michael Skeggs, and Sara Vermillion; Michigan State University ... Kathryn Baker, Christina Berger, Florin Dunca, Dina El-dein, Troy Hendricks, Sang-Yoon Kang, Yo Kim, Figen Lacin, Steve Leibrandt, Nicholas Lynn, Dilip Mandel, Gregary McColley, Chinh Nguyen, Luwi Oluwole, Carl Rose, Michael Shafer, Michael Shao, William Wehbe, and Andrew Yoder; The University of Tulsa ... Ferhat Erdal, Luis Gomez, Floyd Hammond, Jose Severino, and Jin Wang

\section{References Cited}

1. Bird, R.B., W. E. Stewart, and E. N. Lightfoot, 2002, Transport Phenomena, Second Edition, John Wiley \& Sons, New York.

2. Crowe, C.T., J. N. Chung, and T. R. Troutt, 1996, "Numerical Models for Twophase Turbulent Flows," Annual Review of Fluid Mechanics, 28,11-43.

3. Drew, D.A. and S. L. Passman, 1999, Theory of Multicomponent Fluids, Applied Mathematical Series, Volume 135, Springer, New York.

4. Dullian, F.A.L., 1992, Porous Media: Fluid Transport and Pore Structure, Second Edition, Academic Press, San Diego.

5. Gidaspow, D., 1994, Multiphase Flow and Fluidization: Continuum and Kinetic Theory Descriptions Academic Press, Boston.

6. Hornung, U., 1997, Homogenization of Porous Media, Interdisciplinary Applied Mathematics Series, Vol. 6, Springer, 
New York.

7. Ivanov, V. A., F. J. Sarasota, and S. A. Vasquez, 1999, "Multiphase Mixture Model Applied to Cyclone Separators and Bubble Columns", PVP-Vol 397-1, ASME Proceedings on Computational Technologies for Fluid/Thermal/Structural/Chemical Systems with Industrial Applications, Volume 1, Boston, August 1-5.

8. Manninen, M., V. Taivassaio, and S. Kallio, 1996, "On the mixture model for mutiphase flow”, Espoo 1996, Technical Research Center of Finland, VTT Publications 288, 67 pages.

9. Pope, S. B., 2000, Turbulent Flows, Cambridge University Press, Cambridge, UK.

10. Willis, M.S., I. Tosun, W. Choo, G.G. Chase, and F. Desai, 1991, "A DispersedMultiphase Theory and its Application to Filtration," in Advances in Porous Media, Volume 1, M.Y. Corapcioglu ed., Elsevier, Amsterdam.

\section{Biographical Information:}

MARILYN J. AMEY, Associate Professor of Educational Administration, received a BA (1979) in Elementary Education from Wittenberg University, a MA (1985) in Student Personnel in Higher Education from Ohio State University, and a MA (1987) in Public Administration and a Ph.D. (1989) in Higher Education from Pennsylvania State University. Dr.Amey is Chairperson of the HALE Program at Michigan State University and serves as Associate Editor of the Journal of General Education.

ANDRÉ BÉNARD, Assistant Professor of Mechanical Engineering at Michigan State University, received a BS (1988) in Mechanical Engineering from Universite de Sherbrooke, a MS (1990) in Mechanical Engineering from Ecolé Polytechnique de Montreal, and a Ph.D. (1996) in Mechanical Engineering from the University of Delaware.

GEORGE G. CHASE, Professor of Chemical Engineering at The University of Akron, received a BS (1978) in Chemical Engineering and Ph.D. (1989) from The University of Akron. Dr. Chase is director of a Coalescence Research Consortium, has served as director of the Microscale Physicochemical Engineering Center, and has served as the Chairperson of the American Filtration and Separations Society.

EDWARD A. EVANS, Assistant Professor of Chemical Engineering at The University of Akron, received BA (1991) in Engineering from Dartmouth College and a Ph.D. (1998)in Chemical Engineering from Case Western Reserve University. Dr. Evans is the advisor for the undergraduate Chemical Engineering Car Team.

KRISHNAMURTHY JAYARAMAN, Professor of Chemical Engineering at Michigan State University, received his a BS (1971) in Chemical Engineering from the Indian Institute of Technology-Kanpur and a Ph.D. (1975) in Chemical Engineering from Princeton University. Dr. Jayaraman has developed several educational modules and case study designs for industrial workshops in the area of polymer processing.

RAM S. MOHAN, Associate Professor of Mechanical Engineering at the University of Tulsa, received a Ph.D. (1996) and a MS (1992) in Mechanical Engineering from the University of Kentucky and a BS (1984) in Mechanical Engineering fom the University of Kerala, India. Dr. Mohan currently serves as the Symposium Chair of the Manufacturing and Services Symposium for Energy Sources Technology Conference and Exposition of ASME.

STEVEN M. PARKS, Postdoctoral Research Associate and Visiting Lecturer at Michigan State University, received a BS (1991) and Ph.D.(1997) in Chemical Engineering from Michigan State University. Dr. Parks was a DAAD Fellow from 1994-95 at the UniversitätErlangen-Nümberg, Lehrstuhl für Strömungsmechanik and currently is the Organic Director of Merit Laboratories in East Lansing Michigan.

Proceedings of the 2002 American Society for Engineering Education Annual Conference \& Exposition

Copyright $(\mathrm{C})$ 2002, American Society for Engineering Education 
CHARLES A. PETTY, Professor of Chemical Engineering at Michigan State University, received a BS (1966) and a Ph.D. (1970) in Chemical Engineering from The University of Florida. Dr. Petty is director of the Multiphase Flow Facility at Michigan State University and serves as Principal Investigator for the NSF CRCD Multiphase Transport Phenomena project.

SIAMACK A. SHIRAZI, Associate Professor of Mechanical Engineering at The University of Tulsa, received a BS (1981), MS (1983), and Ph.D. (1989) in Mechanical Engineering from The University of New Mexico. Dr. Shirazi is the Director of the Tulsa University Sand Management Projects and the Principal Investigator of the Erosion/Corrosion Research Center at The University of Tulsa.

OVADIA SHOHAM, Professor of Petroleum Engineering at The University of Tulsa, received a BS (1973) in Chemical Engineering from Israel Institute of Technology, a MS (1976) in Chemical Engineering from the University of Houston, and a Ph.D. (1982) in Mechanical Engineering from Tel Aviv University. Dr. Shoham has served as associate director and director of research of the Tulsa University Fluid Flow Projects.

KEITH D. WISECARVER, Associate Professor of Chemical Engineering at the University of Tulsa, received a BS (1979), MS (1983), and Ph.D. (1987) in Chemical Engineering from Ohio State University. Dr. Wisecarver serves as CoPI of the Fundamentals of Delayed Coking DOE/Joint Industry Project and is aregistered Professional Engineer in Oklahoma.

MEI ZHUANG, Associate Professor of Mechanical Engineering at Michigan State University, received a BS (1984) in Mechnical Engineering from Beijing Institute of Aeronautics and Astronautics, a MS (1986) and aPh.D. (1990) in Aeronautics from California Institute of Technology. Dr. Zhuang is a member of the NSF Center for Sensor Materials and the CFD Laboratory at Michigan State University. 